\title{
Feedback-Controlled Lubrication for Reducing the Lateral Vibration of Flexible Rotors supported by Tilting-Pad Journal Bearings
}

Salazar, Jorge Andrés González; Santos, Ilmar

Published in:

Proceedings of 16th Nordic Symposium on Tribology - NORDTRIB 2014

Publication date:

2014

Link back to DTU Orbit

Citation (APA):

Salazar, J. A. G., \& Santos, I. (2014). Feedback-Controlled Lubrication for Reducing the Lateral Vibration of Flexible Rotors supported by Tilting-Pad Journal Bearings. In Proceedings of 16th Nordic Symposium on Tribology - NORDTRIB 2014 Danish Technological Institute.

\section{General rights}

Copyright and moral rights for the publications made accessible in the public portal are retained by the authors and/or other copyright owners and it is a condition of accessing publications that users recognise and abide by the legal requirements associated with these rights.

- Users may download and print one copy of any publication from the public portal for the purpose of private study or research.

- You may not further distribute the material or use it for any profit-making activity or commercial gain

- You may freely distribute the URL identifying the publication in the public portal 


\title{
Feedback-Controlled Lubrication for Reducing the Lateral Vibration of Flexible Rotors supported by Tilting-Pad Journal Bearings
}

\author{
J.G. Salazar ${ }^{1}$, I.F. Santos ${ }^{2}$ \\ ${ }^{1}$ Technical University of Denmark, $2800 \mathrm{Kgs}$. Lyngby, Denmark. \\ ${ }^{2}$ Technical University of Denmark, 2800 Kgs. Lyngby, Denmark.
}

\begin{abstract}
In this work, the feedback-controlled lubrication regime, based on a model-free designed proportionalderivative (PD) controller, is studied and experimentally tested in a flexible rotor mounted on an activelylubricated tilting-pad journal bearing (active TPJB). With such a lubrication regime, both the resulting pressure distribution over the pads and hence the bearing dynamic properties are dynamically modified. The control strategy is focused on reducing the system lateral vibration around its operational equilibrium position in a wide frequency range. For this purpose, servovalves are used as actuators and the flexible rotor lateral movements as feedback control signals. To synthesise the PD controller gains an objective function is optimized in the stabilizing gain domain and then chosen from a subdomain imposed by the servovalves restrictions. The D-decomposition approach expanded to experimentally characterized multi-input multioutput systems is used to determine the stabilizing PD gain domain. The main contribution of this work is to demonstrate the enhancement of the dynamic response of a flexible rotor-bearing system supported by an active TPJB by means of the feedback-controlled lubrication regime featured via PD controllers. Good experimental results are obtained, and a significant improvement of the flexible rotor-bearing system dynamic performance can be experimentally demonstrated.
\end{abstract}

Keywords: active tilting-pad journal bearing, feedback-controlled lubrication, PD controllers, multi-input multi-output systems, vibration reduction.

*Corresponding author: Jorge González Salazar (jgsal@mek.dtu.dk).

\section{INTRODUCTION}

For several decades the fluid film journal bearings have been used as a standardized machine element which can be easily specified for a new machine. Most of the earlier experienced drawbacks, such as poor energy efficiency, high bearing wear and instability problems have been satisfactorily addressed with the current designs. Nevertheless new requirements are continuously emerging and nowadays higher efficiency performance, higher operational conditions of velocities and loads, lower vibration levels as well as the capability of adjusting their dynamics for a maintenance free operation are currently requested [1]. In such a framework, tilting-pad journal bearings (TPJBs) - well known type of fluid film bearing with superior stability properties [2] - have naturally evolved to mechatronic machine elements by means of the addition of control systems for responding to these new requirements. Different types of actuators have been studied $[3,4,5,6]$ nonetheless the one presented in this work is based on the hydraulic type. TPJBs with electronic radial oil injection or actively-lubricated TPJBs or simply active TPJBs $[7,8]$ are provided with servovalves, which inject high pressurized lubricant into the bearing clearance through nozzles placed in orifices commonly drilled in the middle of the pad surface. For such mechatronic bearings, control signals govern the servovalves, regulating the lubricant injection flow and hence the pressure distribution composed by the hydrodynamic and hydrostatic effects. As a result, the bearing dynamic properties are modified. Mathematical models for active TPJBs follow the modelling of conventional TPJBs and have evolved from the EHD approach [9] to the current TEHD approach $[10,11]$, besides of accounting for the pivot flexibility, the heat transfer to the solid and fluid surroundings as well as for the servovalves and pipes dynamics.

Depending on whether control laws are used or not, different lubrication regimes can be featured. The used control strategy also defines the developed lubrication regime. Within the active TPJBs framework, earlier theoretical studies $[12,13,14]$ have been focused on including the control laws into the model for a rigid rotor-active TPJB test bench, however few studies have been focused on flexible rotor systems. It can be stated that there are roughly two ways of reducing the lateral vibrations of a rotor-bearing system, the first one by changing its equilibrium position, and a second one by affecting the bearing properties around the 
equilibrium. A previous work [15] on the same flexible rotor system was focused on exploring the reduction on the system lateral response by changing the journal equilibrium position via an integral controller. The second way for reducing the system lateral vibrations can be reached by implementing the feedbackcontrolled lubrication regime based on proportionalderivative (PD) controllers. It has been shown theoretically that these controller gains act directly on the bearing stiffness and damping parameters [16]. Thus, the lateral vibrations can be controlled around the shaft operational equilibrium position.

The main original contributions of this work are the design and implementation of a PD controller to feature the feedback-controlled lubrication regime with the aim of reducing the lateral vibration of a flexible rotor-active TPJB test bench. To synthesise the PD controller gains an objective function is optimized in the stabilizing gain domain and then the set of the stabilizing PD-gains are chosen from a subdomain imposed by the servovalves restrictions. The Ddecomposition approach $[17,18,19]$, previously used with experimentally described single-input singleoutput (SISO) systems [20,21], is now extended to determine the stabilizing gain domain within the controller parameter space for an experimentally characterized multi-input multi-output (MIMO) system. The dynamic characterization of the whole system (servovalves + mechanical system + sensors) required for designing the controller is provided by means of a model-free characterization in the form of measured frequency response functions (FRFs) obtained exciting via the servovalves.

\section{EXPERIMENTAL FACILITIES}

\subsection{The Flexible Rotor-Bearing Test Stand}

The test stand, which is comparable to an industrial machine, is an $87 \mathrm{~kg}$ overhung rotor mounted on a $1150 \mathrm{~mm}$ flexible shaft supported by the active TPJB and by a ball bearing at its driven side. The test stand is belt-driven by means of a layshaft flexibly coupled to the shaft at its driven side. The power is supplied by a 4 HP AC motor which through a frequency driver enables the test stand to run up to $7000 \mathrm{rpm}$. The test stand allows for studying the dynamic behavior of flexible rotor-bearing systems when different feedback-controlled lubrication regimes - depending on the adopted control law - are developed with the active TPJB. Two ways of exciting the test stand are currently enabled to carry out modal parameter identification. The first one, by means of an excitation bearing placed at the free end and connected to an electromagnetic shaker through stingers and a force transducer to apply unidirectional forces. The second one, an active magnetic bearing (AMB) placed next to the active TPJB, toward the driven end side, which can

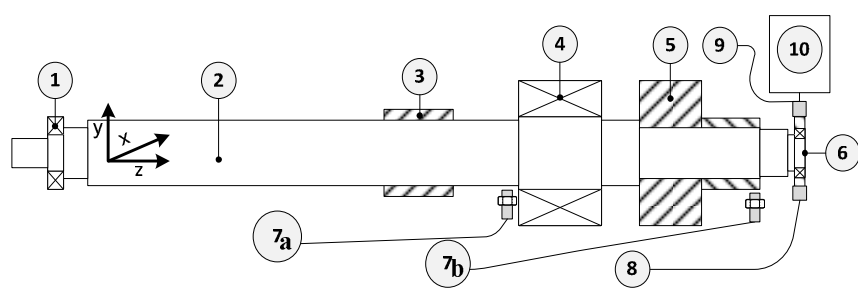

Figure 1: An overview scheme of the tilting-pad journal bearing test stand. (1): ball bearing. (2): flexible shaft. (3): $A M B$ rotor. (4): tilting-pad journal bearing. (5): disc. (6: excitation bearing. (7): proximity probes. (8): accelerometer. (9): force transducer. (10): electromagnetic shaker. The orthogonal reference frame is included.

exert forces over the rotor in all possible directions without any physical link to it. Figure 1 shows an overview scheme of the test stand with its primary parts and the experimental instrumentation setup used for this work. The used reference frame is also included in the scheme.

\subsection{The Controllable Journal Bearing}

The controllable/active bearing is a tilting-pad journal bearing with 4 bronze pads in a LBP configuration. The pads are rocker pivoted in the circumferential middle of the pad, i.e. with an offset of 0.5. Further design parameters are included in Table 1. The active or controllable feature of the bearing is developed by an electronic radial oil injection system as proposed by [8]. This injection system superimposes an hydrostatic pressure over the hydrodynamic pressure distribution by injecting pressurized oil between the journal-pad clearance trough a nozzle placed in the pad middle. The high pressure oil flow is controlled by two highfrequency response servovalves, each one is coupled to a pairwise of counter pads. The lubricant is supplied for the conventional and for the active lubrications by a low (max. 2 bar) and a high (max. 100 bar) pumping units respectively. Figure 2 depicts an scheme of the radial oil injection system overlapped to a picture of the active bearing. Proximity probes used for monitoring and feeding back controllers are also included (position 7a in Figure 1).

The active bearing is capable to operate under three different lubrication regimes, namely; a) the conventional or hydrodynamic lubrication regime, also called "passive", b) the hybrid or adjustable lubrication regime, which is a combination of the hydrodynamic case with an hydrostatic effect added by the injection system, and c) the feedback-controlled or active lubrication regime whose hydrostatic contribution to the pressure field is controlled by well-tuned control gains. Commonly, the controller is digitally implemented in a FPGA or similar hardware with real time processing capabilities. 


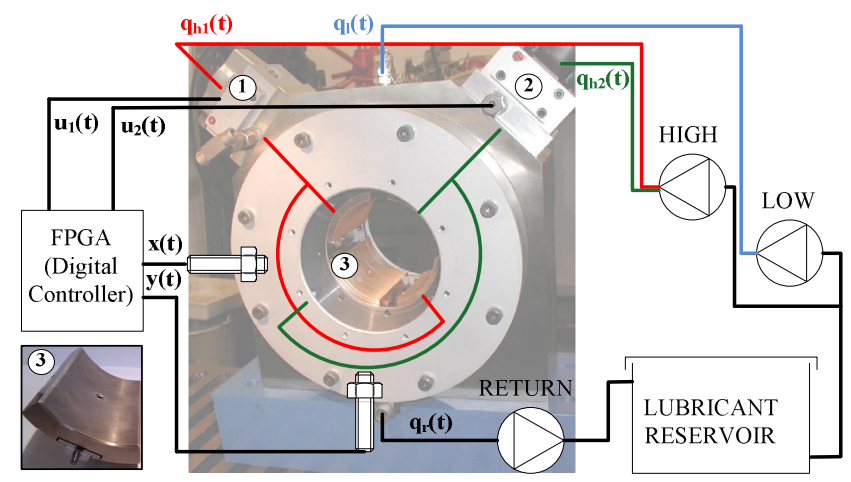

Figure 2: The controllable tilting-pad journal bearing with a scheme of the radial oil injection control system. Both lubrication pumping units (low and high) and the proximity probes are included. (1), (2): servovalves. (3): the active pad, with an orifice in its surface middle.

\section{PD CONTROLLER DESIGN}

When the control strategy is focused on diminishing the vibration around the equilibrium position the most suitable controllers for such purpose are the PD controllers $[13,22]$. This is because their gains act over the instant error and its time derivate (related with the system position $y(t)$ and velocity $\dot{y}(t)$ ) instead of acting upon the cumulative error (related with the mean position value $\bar{y}(t)$ ) as for the case of integral controllers, which are more suitable for affecting the system equilibrium position. In order to properly design the PD controller, a reliable dynamic plant characterization in a wide frequency range is needed instead of quasi-static calibration curves used, for instance, in the case of integral controllers. Owing to the changes in the system dynamic with the operational conditions, produced mainly by the gyroscopic effect and by the non-linear bearing properties, different operational condition are taken into account. Table 2 summarizes the operational conditions considered for the plant characterization

Table 1: Conventional and controllable design parameters of the controllable tilting-pad journal bearing.

\begin{tabular}{lcc}
\hline \multicolumn{1}{c}{ Parameter } & Value & Units \\
\hline \hline Conventional Design & & $\mathrm{mm}$ \\
\hline Journal radius $(\mathrm{R})$ & 49.89 & $\mathrm{~mm}$ \\
Pad inner radius $\left(\mathrm{R}_{\mathrm{p}}\right)$ & 50 & degrees \\
Pad aperture angle $\left(\alpha_{\mathrm{p}}\right)$ & 69 & $\mathrm{~mm}$ \\
Pad width $(\mathrm{L})$ & 100 & $\mathrm{~mm}$ \\
Pad thickness $(\mathrm{t})$ & 14 & $\mu \mathrm{m}$ \\
Nominal radial clearance $\left(\mathrm{c}_{\mathrm{b}}\right)$ & 110 & $\mu \mathrm{m}$ \\
Assembly radial clearance $\left(\mathrm{c}_{\mathrm{p}}\right)$ & 83 & - \\
Lubrication oil type & ISO VG22 & $\mathrm{L} / \mathrm{min}$ \\
Oil flow & 1 & $\mathrm{~N}$ \\
Bearing applied load & 890 & - \\
\hline Controllable Design & & - \\
\hline Servovalve type & MOOG E760-912 & $\mathrm{Hz}$ \\
Servovalve configuration & 4 ways, spool valve & $\mathrm{mm}$ \\
Cutoff frequency $($ at 210 bar $)$ & 350 & $\mathrm{~mm}$ \\
Injector orifice diameter $\left(\mathrm{d}_{0}\right)$ & 3.3 & \\
Injector orifice length $\left(\mathrm{L}_{0}\right)$ & 21 &
\end{tabular}

and the controller design, hereafter referred as the cases from \#1(a) to \#3(c).

\subsection{Model-Free Plant Characterization}

The plant dynamic can be described either by theoretical or experimental models. Working with theoretical models is not a straightforward task due to the complexity that they normally reach for describing more precisely their behavior. On the other hand, since the work goal is to demonstrate the effectiveness of the feedback-controlled lubrication, the usage of experimental models is enough for the work purpose. In such case, all uncertainties yielded by theoretical models can be disregarded since the experimental models take them already into account. The experimental plant dynamic characterization is carried out by means of the measured frequency response functions (FRFs) obtained via the servovalves and defined between the system input and output variables, i.e. in this case between the servovalves control signals $u(t)$ and the shaft lateral movements $y(t)$, for instance, at the bearing housing position or at the shaft free end (positions $7 \mathrm{a}$ and $7 \mathrm{~b}$ in Figure 1). Therefore, the plant characterization includes not only the mechanical system dynamic but also the servovalves and proximity probes dynamic.

Since the 4 pads bearing is in a LBP configuration, i.e. the orthogonal directions used for describing the applied load and also the measurements are shifted 45 degrees related to the servovalves orthogonal directions, the bearing can be considered as a twoinput two-output (TITO) system for the control design aim. Contrarily, if the bearing design were a LOP configuration, theoretically the bearing might be considered as a SISO system at each direction instead, such as in [13], but neglecting potential cross effects of the TPJB, the gyroscopic effect and probably unequal servovalves dynamics. Nevertheless in a more general sense, as the output, i.e. the lateral displacements $y(t)$, can be measured in any section of the flexible shaft wide span, the whole mechanical system might be considered as a MIMO system which turn the control design more challenging. In this work the whole plant is considered as a TITO system for the controller design purpose.

Figure 3 summarizes the plant dynamic characterization (FRFs) obtained by means of the servovalves and exciting with a bidirectional chirp control signal. Two different positions of the flexible

Table 2: Operational conditions used for the model-free dynamic plant characterization and the controller design.

\begin{tabular}{rcccc}
\hline \hline & $\Omega$ & $(\mathbf{a})$ & $\mathbf{( b )}$ & $\mathbf{( c )}$ \\
Case & $\mathbf{r p m}$ & $\mathbf{P}_{\text {sup }}[\mathbf{b a r}]$ & $\mathbf{P}_{\text {sup }}[\mathbf{b a r}]$ & $\mathbf{P}_{\text {sup }}[\mathbf{b a r}]$ \\
\hline$\# \mathbf{1}$ & 1000 & 30 & 50 & 70 \\
$\# \mathbf{2}$ & 2500 & 30 & 50 & 70 \\
$\# \mathbf{3}$ & 4000 & 30 & 50 & 70 \\
\hline \hline
\end{tabular}



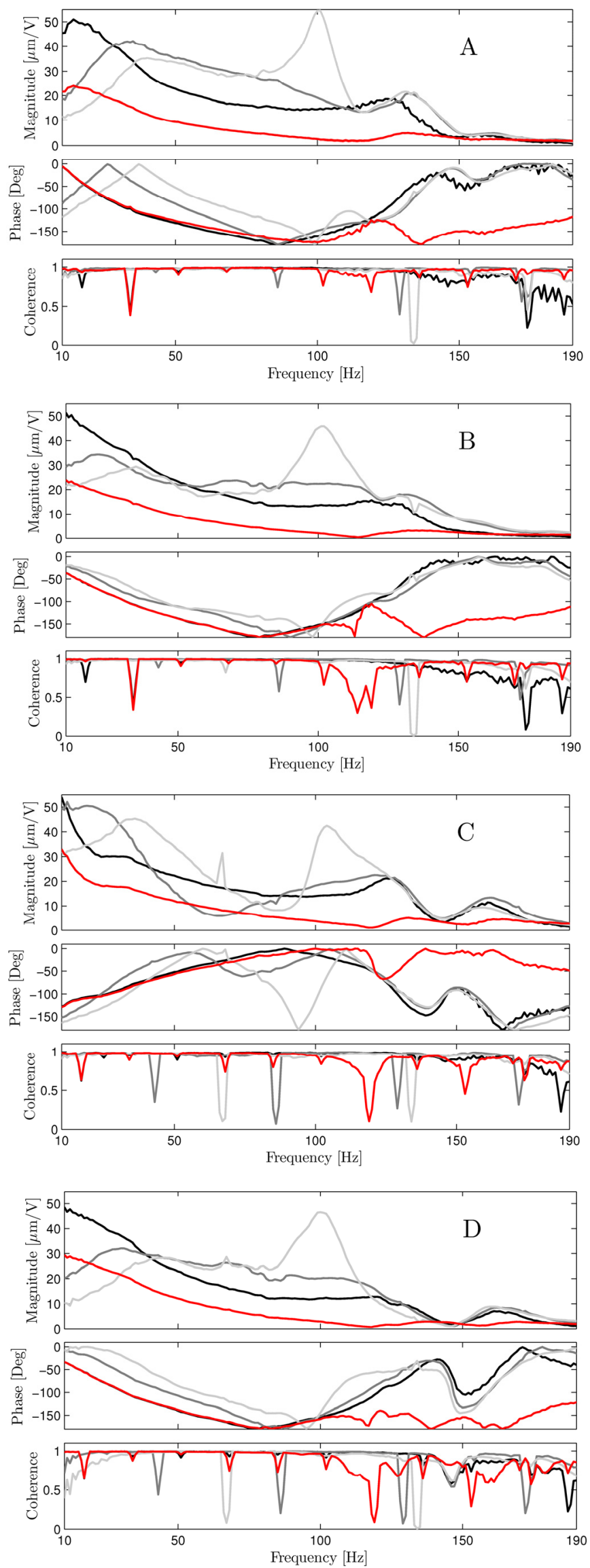

$-7 \mathrm{~b}$, Cond $1 \mathrm{c}-7 \mathrm{~b}$, Cond $2 \mathrm{c}-7 \mathrm{~b}$, Cond $3 \mathrm{c}-7 \mathrm{a}$, Cond $1 \mathrm{c}$

Figure 3: Dynamic characterization of the MIMO system via servovalves at position $7 a$ (red) and $7 b$ (black) of Figure 1 for the operational condition of case \#1(c). A: $P_{x 1}(\mathrm{j} \omega)$. B: $P_{x 2}(\mathrm{j} \omega), \boldsymbol{C}: P_{y 1}(\mathrm{j} \omega), \boldsymbol{D}: P_{y 2}(\mathrm{j} \omega)$. Cases \#2(c) and \#3(c) are also included in gray colors for position $7 b$. shaft are depicted for the operational condition \#1(c), positions 7a (red) and 7b (black) of the Figure 1. It is also shown in gray colors for position $7 \mathrm{~b}$, the cases $\# 1$ (a) and \#1(b) to depict the influence of the angular velocity in the system behavior. For the sake of briefness the rest of cases of Table 2 have been omitted. In Figure $\mathbf{3}$ each row correspond to an orthogonal shaft displacement $(x(t)$ and $y(t)$ directions) while the rotor is excited by each servovalve control signal $\left(u_{1}(t)\right.$ and $\left.u_{2}(t)\right)$ at the time, sorted in columns. Hence the plots identified as $\mathbf{A}, \mathbf{B}, \quad \mathbf{C}$ and $\mathbf{D}$ in Figure $\mathbf{3}$ show the $P_{x 1}(j \omega), P_{x 2}(j \omega), P_{y 1}(j \omega)$ and $\quad P_{y 2}(j \omega) \quad$ FRF components respectively. As expected, due to the test rig configuration (overhanging disc), for a defined operational condition, e.g. \#1(c), the higher responses of the system are obtained at the shaft free end (position 7b) in comparison with the bearing housing (position 7a). On the other hand, better results are obtained for the coherence function at the same position up to roughly $150 \mathrm{~Hz}$. Therefore the FRFs of position $7 \mathrm{~b}$ will be used hereafter for the control design purpose. Analyzing the selected FRF shapes, it can be mainly noticed two facts, i) at low frequencies, i.e. below $100 \mathrm{~Hz}$, the system dynamic is strongly affected by the servovalves dynamic. This can be inferred when comparing these FRFs with the one obtained by the parameter identification test of section 3.6, for which the servovalves dynamic does not influence the results because the system is excited with the electromagnetic shaker and the proximity sensors behavior is considered as linear and, ii) at high frequencies, i.e. above $100 \mathrm{~Hz}$, it can be identified at the vertical direction, two resonant zones at $125 \mathrm{~Hz}$ and $165 \mathrm{~Hz}$ approximately whereas in the horizontal direction, it can be only identified the first one.

\subsection{The Closed-Loop MIMO Plant Configuration}

Figure 4 depicts the plant block diagram in an open (continuous line) and closed-loop (dashed line) configurations in which all variables are defined in the frequency domain instead of Laplace domain to work with the experimental data, i.e. $\mathrm{s}=j \omega$, where $j$ denotes the complex unity. $\mathbf{R}(j \omega)$ stands for the reference signal, $\mathbf{E}(j \omega)$ for the error, $\mathbf{U}(j \omega)$ for the control signal, $\mathbf{D}(j \omega)$ for the system disturbance (input) and $\mathbf{Y}(j \omega)$ for the system response (output). $\mathbf{P}(j \omega)$ is the plant transfer function in the open-loop configuration and $\mathbf{C}(j \omega)$ denotes the PD controller transfer function. It is assumed that the plant in the open-loop configuration behaves as a stable linear time invariant system when it is operating at each operational condition of Table 2. Hence the closedloop transfer function $\mathbf{G}(j \omega)$ of the plant is defined by: 


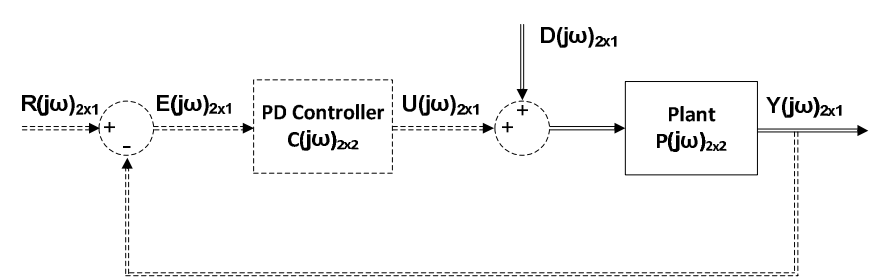

Figure 4: Open (continuous line) and closed-loop (dashed line) plant block diagrams. $\mathbf{R}(j \omega)$ : reference signal. $\mathbf{E}(j \omega)$ : error. $\mathbf{U}(j \omega)$ : control signal. $\mathbf{D}(j \omega)$ : system disturbance $\mathbf{Y}(j \omega)$ : system output. $\mathbf{P}(j \omega)$ : the plant response. $\mathbf{C}(j \omega)$ : PD controller.

$\boldsymbol{G}(j \omega)=\frac{\mathrm{Y}(j \omega)}{\mathrm{D}(j \omega)}=[\boldsymbol{I}+\boldsymbol{P}(j \omega) \boldsymbol{C}(j \omega)]^{-1}[\boldsymbol{P}(j \omega)]$

where $I$ denotes the identity matrix. Two matrices define the closed-loop transfer function of the plant defined in Equation 1, i.e. the open-loop plant transfer function $\mathbf{P}(j \omega)$ which is completely known and experimentally defined for each operational condition by the curves of the model-free plant characterization presented previously in Figure 3. i.e.:

$$
\boldsymbol{P}(j \omega)=\left[\begin{array}{ll}
P_{x 1}(j \omega) & P_{x 2}(j \omega) \\
P_{y 1}(j \omega) & P_{y 2}(j \omega)
\end{array}\right]
$$

and the PD controller transfer function which must be designed. Different structures can be adopted for the PD controller transfer function matrix $\mathbf{C}(j \omega)$ when dealing with MIMO system, commonly referred as the pairing problem. These structures are based on the loop interactions and assessed in terms of their interaction measure [23]. For instance, a dedicate PD controller for each matrix element of $\mathbf{C}(j \omega)$ requires synthesizing 8 controller gains. Contrarily, a decentralized matrix, i.e. each control signal $u_{i}(t)$ is commanded for only one error signal $e_{i}(t)$, would require the synthesis of 4 controller gains. A simpler form, is to work with the same PD controller for all matrix elements of $\mathbf{C}(j \omega)$, for which only one set of controller gains must be determined. This adopted MIMO structure is defined as:

$\boldsymbol{C}(j \omega)=\left[\begin{array}{cc}C_{P D}(j \omega) & C_{P D}(j \omega) \\ -C_{P D}(j \omega) & C_{P D}(j \omega)\end{array}\right]$

where the term $C_{P D}(j \omega)$ is the standard SISO transfer function for the PD controller defined in the frequency domain by:

$C_{P D}(j \omega)=\frac{U(j \omega)}{E(j \omega)}=k_{p}+j \omega k_{d}$

isolating the PD controller complex gain of Equation 4, Equation 3 can be rewritten conveniently as:
$\boldsymbol{C}(j \omega)=k_{p}+j \omega k_{d}\left[\begin{array}{cc}1 & 1 \\ -1 & 1\end{array}\right]$

with such structure, the servovalve control signal $u_{1}(t)$ is managed by the sum of the errors $e_{y}(t)+$ $e_{x}(t)$ and the servovalve control signal $u_{2}(t)$ is managed by the subtraction of the errors signals $e_{y}(t)-e_{x}(t)$. This is expressed in the frequency domain as:

$$
\begin{gathered}
\boldsymbol{U}(j \omega)=C_{P D}(j \omega)\left[\begin{array}{cc}
1 & 1 \\
-1 & 1
\end{array}\right] \boldsymbol{E}(j \omega) \\
{\left[\begin{array}{l}
u_{1}(j \omega) \\
u_{2}(j \omega)
\end{array}\right]=C_{P D}(j \omega)\left[\begin{array}{l}
e_{y}(j \omega)+e_{x}(j \omega) \\
e_{y}(j \omega)-e_{x}(j \omega)
\end{array}\right]}
\end{gathered}
$$

\subsection{Setting up the reference signal $R(t)$ and the Control Law $U(t)$}

Once the PD controller structure is defined the next step is to define the error signals governing the PD controller by setting the reference signals. In time domain the error signals are defined by $\boldsymbol{E}(t)=\boldsymbol{R}(t)-$ $\boldsymbol{Y}(t)$, i.e.:

$$
\left[\begin{array}{l}
e_{x}(t) \\
e_{y}(t)
\end{array}\right]=\left[\begin{array}{l}
r_{x}(t) \\
r_{y}(t)
\end{array}\right]-\left[\begin{array}{l}
x_{0}+x(t) \\
y_{0}+y(t)
\end{array}\right]
$$

where the subscripts define the orthogonal directions and the constants $x_{0}$ and $y_{0}$ are the equilibrium position given by the mean value of the displacement sensor signals for the current operational condition. When dealing with an integral controller, the reference signal is set as the new desired equilibrium position, that is $\left(x_{0}^{\prime}, y_{0}^{\prime}\right)$, but when dealing with PD controllers and since the control strategy has the goal of reducing the lateral vibration around the operational equilibrium position $\left(x_{0}, y_{0}\right)$, the reference signal can be set as the same operation equilibrium point, $\boldsymbol{R}(t)=\boldsymbol{Y}_{\mathbf{0}}=$ $\left[\begin{array}{ll}x_{0} & y_{0}\end{array}\right]^{T}$, then the error at each orthogonal direction can be defined as the vibration around the operational equilibrium point as:

$\left[\begin{array}{l}e_{x}(t) \\ e_{y}(t)\end{array}\right]=\left[\begin{array}{l}x_{0} \\ y_{0}\end{array}\right]-\left[\begin{array}{l}x_{0}+x(t) \\ y_{0}+y(t)\end{array}\right]=-\left[\begin{array}{l}x(t) \\ y(t)\end{array}\right]$

or expressed in frequency domain as:

$\boldsymbol{E}(j \omega)=-\boldsymbol{Y}(j \omega)$

substituting Equation 10 into Equation 6 leads the following control law for the servovalves:

$\boldsymbol{U}(j \omega)=-C_{P D}(j \omega)\left[\begin{array}{cc}1 & 1 \\ -1 & 1\end{array}\right]\left[\begin{array}{l}x(j \omega) \\ y(j \omega)\end{array}\right]$

expanding Equation 11, the control law is written as: 
$\left[\begin{array}{l}u_{1}(j \omega) \\ u_{2}(j \omega)\end{array}\right]=-\left(k_{p}+j \omega k_{d}\right)\left[\begin{array}{l}y(j \omega)+x(j \omega) \\ y(j \omega)-x(j \omega)\end{array}\right]$

or in time domain as:

$u_{1}(t)=-k_{d}(\dot{y}(t)+\dot{x}(t))-k_{p}(y(t)+x(t))$

$u_{2}(t)=-k_{d}(\dot{y}(t)-\dot{x}(t))-k_{p}(y(t)-x(t))$

\subsection{Controller Gain Synthesis}

To synthesise the PD-controller gains $k_{p}$ and $k_{d}$ of Equation 4 an optimization problem is formulated. In such a case, an objective function is pursued to be maximized/minimized within the stabilizing domain of the controller gains defined in the parameter space $k_{p} \times k_{d}$. To define the objective function, the control strategy of suppressing the vibration amplitudes is kept in mind for the whole interested frequency domain. For defining the stabilizing gain domain, the Ddecomposition method $[17,18,19]$ is used. Then, some restrictions related with the servovalves control signals are applied.

The objective function $\mathfrak{J}\left(k_{p}, k_{d}\right)$ : The aim of using a PD controller is to reduce the lateral vibration of the system. Therefore, it is pursued that the amplitude of the closed-loop system response $\boldsymbol{G}(j \omega)$ be lower than amplitude of the open-loop system response $\boldsymbol{P}(j \omega)$ if possible in the whole frequency range defined as $\mathfrak{D}_{\omega} \triangleq\left\{\omega \in \mathcal{R} \mid 0<\omega<\omega_{\max }\right\}$. If the phase margin specification is neglected, then the following function regarding the gain margin can be defined for each frequency $\omega$ :

$\boldsymbol{F}\left(j \omega, k_{p}, k_{d}\right)=|\boldsymbol{P}(j \omega)|-\left|\boldsymbol{G}\left(j \omega, k_{p}, k_{d}\right)\right| ; \forall \omega \in \mathfrak{D}_{\omega}$

where $|\cdot|$ stands for the absolute value. Therefore, if the area under the curve is used as an index to assess the performance of the controller in the whole frequency domain $\mathfrak{D}_{\omega}$, then the following objective function can be defined:

$\mathcal{J}\left(k_{p}, k_{d}\right)=\int_{\omega_{\min }}^{\omega_{\max }} \mathcal{F}\left(j \omega, k_{p}, k_{d}\right) d \omega$

$\mathcal{J}\left(k_{p}, k_{d}\right)=\int_{\omega_{\min }}^{\omega_{\max }}|\boldsymbol{P}(j \omega)|-\left|\boldsymbol{G}\left(j \omega, k_{p}, k_{d}\right)\right| d \omega$

The pair of controller gains $\left(k_{p}^{*}, k_{d}^{*}\right)$ which maximize the index of Equation 16 is defined by:

$\mathfrak{J}^{*}=\max \left\{\mathcal{J}\left(k_{p}^{*}, k_{d}^{*}\right)\right\} ; k_{p}^{*}, k_{d}^{*} \in \mathfrak{D}_{k}$

The stabilizing gain domain $\mathfrak{D}_{k}$ : Different methods for determining the stabilizing gain domain can be found in literature [24,25,26,27]. However, most of them are aimed at synthesizing the gains of decentralized controllers for theoretical or experimental SISO system models. In [20] and [21] the D-decomposition method is used to find the stabilizing regions of the PD-gains for a SISO system from experimental FRFs data. In this work, the same method is used but extending its applicability to MIMO systems. The D-decomposition method, developed by Neimark and summarized in $[17,18,19]$, divides the controller parameter space $\left(k_{p} \times k_{d}\right)$ into roots invariant regions for which the number of stable and unstable poles remains constant. For experimental MIMO plant representations, the stability in such areas can be assessed by the generalized (MIMO) Nyquist stability criterion [30]. For MIMO systems the stability invariant region boundaries are defined by equaling the determinant of the inverse of the sensitivity function to zero $[18,19]$, i.e.:

$\operatorname{det}(\boldsymbol{I}+\boldsymbol{P}(j \omega) \boldsymbol{C}(j \omega))=0$

considering the plant characterization $\boldsymbol{P}(j \omega)$ of Equation 2 and the PD controller $\boldsymbol{C}(j \omega)$ defined by Equation 3 and the identity matrix $I$, Equation 18 can be reduced to:

$$
\operatorname{det}(\boldsymbol{P}(j \omega)) C_{P D}^{2}+\left(p_{x 1}-p_{x 2}+p_{y 1}+p_{y 2}\right) C_{P D}=0
$$

Equation 19 is a second order complex equation with one complex variable $C_{P D}$. Rearranging Equation 19 in real and complex terms, the following two equations can be obtained:

$$
\begin{gathered}
a_{r e} k_{p}^{2}-\omega^{2} a_{r e} k_{d}^{2}-2 a_{i m} \omega k_{p} k_{d}+b_{r e} k_{p}-b_{i m} \omega k_{d}=-1 \\
a_{i m} k_{p}^{2}-\omega^{2} a_{i m} k_{d}^{2}+2 a_{r e} \omega k_{p} k_{d}+b_{i m} k_{p}+b_{r e} \omega k_{d}=0
\end{gathered}
$$

where the terms $a_{r e}, a_{i m}, b_{r e}$ and $b_{i m}$ are defined by:

$$
\begin{aligned}
& a_{r e}=\operatorname{Re}\{a\}=\operatorname{Re}\{\operatorname{det}(\boldsymbol{P}(j \omega))\} \\
& a_{i m}=\operatorname{Im}\{a\}=\operatorname{Im}\{\operatorname{det}(\boldsymbol{P}(j \omega))\} \\
& b_{r e}=\operatorname{Re}\{b\}=\operatorname{Re}\left\{p_{x 1}-p_{x 2}+p_{y 1}+p_{y 2}\right\} \\
& b_{i m}=\operatorname{Im}\{b\}=\operatorname{Im}\left\{p_{x 1}-p_{x 2}+p_{y 1}+p_{y 2}\right\}
\end{aligned}
$$

Equation 20 is a system of two equations with two variables - the controller gains $k_{p}$ and $k_{d}$ - which can be solved numerically and taking into account that the solution should not be the singular solution and that the controller gains $k_{p}$ and $k_{d}$ must be real values.

The restricted gain subdomain $\overline{\mathfrak{D}}_{k}$ : a restricted gain subdomain can be defined due to the maximum allowed values of the control signals $\boldsymbol{U}(t)$ which in turn limit the PD gains values too. The control signals can be limited by the D/A converter $( \pm 10 \mathrm{~V})$, by the linear range of the servovalves $( \pm 0.5 \mathrm{~V}$ over their 


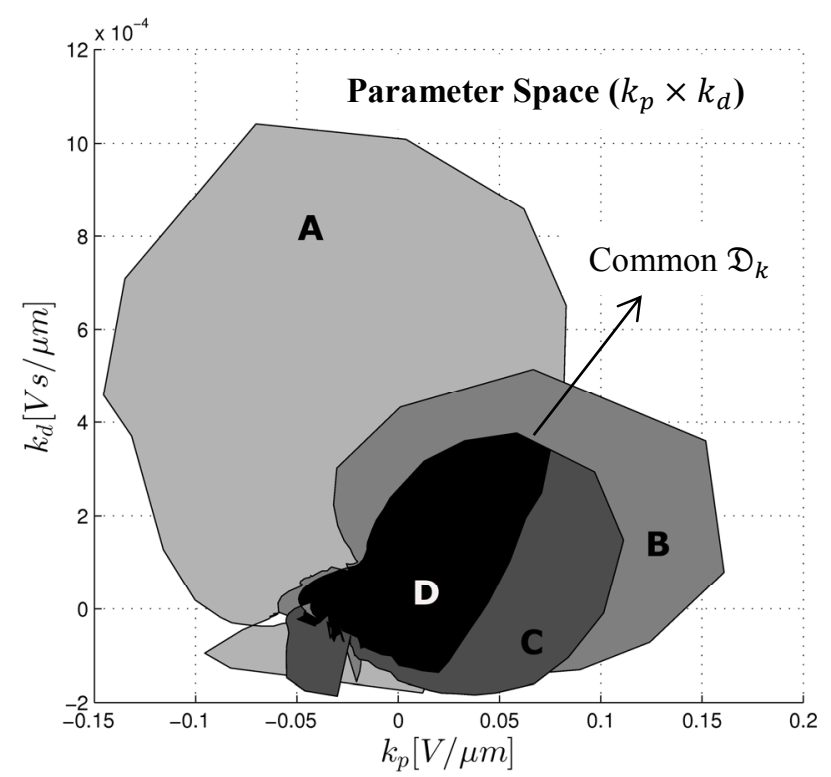

Figure 5: Stabilizing gains area $\mathfrak{D}_{\boldsymbol{k}}$ defined by the Ddecomposition method for the MIMO system. A: case \#1(c), $\boldsymbol{B}$ : case \#2(c), $\boldsymbol{C}$ : case \#3(c) and $\boldsymbol{D}$ : common stabilizing area from the intersection of $\boldsymbol{A}, \boldsymbol{B}$ and $\boldsymbol{C}$ areas.

offset values) or by the full servovalves range $( \pm 2 \mathrm{~V})$. They can also be limited, for instance, to limit the system response at the active TPJB as a fraction of the assembly clearance, to avoid surface contact between the shaft and the bearing. In this work, due to some uncertainties on the linear range of the servovalves, since there are not spool position feedback signals, the control signal are restricted to their full operational range, limiting the values of the PD controller gains $k_{p}$ and $k_{d}$.

Synthesized PD controller gains: Figure 5 depicts the stabilizing domains in the parameter space found by means of the D-decomposition method for the cases $\# 1(\mathrm{c}), \# 2$ (c) and \#3(c) of Table 2 and identified by $\mathbf{A}$, $\mathbf{B}$ and $\mathbf{C}$ respectively. For obtaining these areas, Equation 19 was used with the data provided from the experimental plant characterization of Figure 3 . Results are very sensitive to the experimental data quality, which are improved as the pressure of the high pressure supply unit is increased. With the higher pressure of 70 bar considered (cases (c) in Table 2) the information contained between 20 and $140 \mathrm{~Hz}$ have provided acceptable values of all coherence functions and have been used for calculations. In Figure 5, the black area denoted with $\mathbf{D}$ represents the intersection of all areas and it is considered as the common stabilizing gain domain $\mathfrak{D}_{k}$ for determining the pair of gain values $\left(k_{p}, k_{d}\right)$ which can be indistinctly used for all operational conditions. For analyzing the stability of the closed-loop system the Nyquist stability criterion for MIMO system was employed as stated in [30]. Three pairs of the controller gains $\left(k_{p}, k_{d}\right)$ were randomly selected and assessed for stability. The first

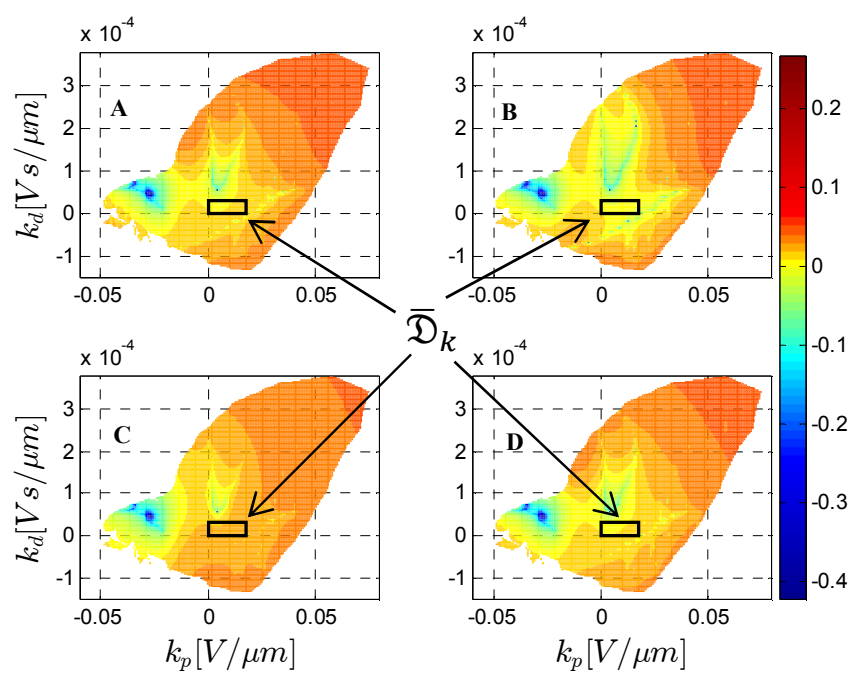

Figure 6: Objective function for the MIMO system under operational condition \#1 (c). A: $\mathcal{J}_{x 1}\left(\boldsymbol{k}_{\boldsymbol{p}}, \boldsymbol{k}_{\boldsymbol{d}}\right), \boldsymbol{B}: \mathcal{J}_{x 2}\left(\boldsymbol{k}_{\boldsymbol{p}}, \boldsymbol{k}_{\boldsymbol{d}}\right)$, C: $\mathcal{J}_{y 1}\left(\boldsymbol{k}_{\boldsymbol{p}}, \boldsymbol{k}_{\boldsymbol{d}}\right), \quad \boldsymbol{D}: \mathcal{J}_{y_{2}}\left(\boldsymbol{k}_{\boldsymbol{p}}, \boldsymbol{k}_{\boldsymbol{d}}\right)$. The restricted gain subdomain $\overline{\mathfrak{D}}_{k}$ is included.

one, inside the black $\mathbf{D}$ area, the second one at the boundary and the third out of the area. Since the plant is proper defined, i.e. it has not unstable poles, no encirclements of the origin in the Nyquist plot are obtained in the closed-loop configuration, neither a pass through the origin, and hence the $\mathbf{D}$ area is stable.

Figure 6 shows the objective function $\mathfrak{J}\left(k_{p}, k_{d}\right)$ defined in Equation 15 normalized by its maximum absolute value under the operational conditions \#1(c) within the common stabilizing domain $\mathfrak{D}_{k}$. All other cases have been omitted for the sake of briefness. Since the objective function $\mathcal{J}\left(k_{p}, k_{d}\right)$ is defined based on the open and closed-loop transfer function matrices (see Equation 16) it is also defined as a matrix and it yields different values for the different input/output relationships. The subplots $\mathbf{A}, \mathbf{B}, \mathbf{C}$ and $\mathbf{D}$ show the different relationship between the servovalve control signals and the system response in the same form as define previously for Figure 3. In general, it can be noticed that better values of the objective function are obtained for higher values of the gains. However, the servovalve control signal ranges restrict the area from which the PD controller gains can be selected and the subdomain $\overline{\mathfrak{D}}_{k}$ must be determined. A simple experimental test was carried out to determine the restricted subdomain. The proportional $k_{p}$ and derivative $k_{d}$ gains were tuned one at the time until the servovalves reached their saturation limits of $\pm 2 \mathrm{~V}$ over their offset values $(2.5 \mathrm{~V}$ and $2.05 \mathrm{~V}$ for the servovalves 1 and 2 respectively). Limit values of $k_{p}=0.018 \mathrm{~V} / \mu \mathrm{m}$ and $k_{d}=3 \cdot 10^{-5} \mathrm{Vs} / \mu \mathrm{m}$ were determined defining a restricted rectangle from which the gains can be selected. This rectangle of the subdomain $\overline{\mathfrak{D}}_{k}$ is included in the plot of the objective function in Figure 6. 
Table 3 summarizes three different PD controllers selected from the subdomain $\overline{\mathfrak{D}}_{k}$ to be digitally implemented in the FPGA hardware and experimentally tested. The PD controller 1 was randomly chosen. The other two controllers were obtained by increasing one gain at the time to see their effect on the system response, i.e. for the PD controller 2 the proportional gain was increased from 0.006 to $0.01 \mathrm{~V} / \mu \mathrm{m}$ and for the PD controller 3 the derivative gain was increased from $2 \cdot 10^{-5}$ to $3 \cdot 10^{-5} \mathrm{Vs} / \mu \mathrm{m}$.

\section{EXPERIMENTAL RESULTS}

\subsection{Experimental Procedure}

To implement the controllers of Table 3 the shaft displacements were obtained from the proximity probes at point $7 \mathrm{~b}$ in Figure 1 whereas the velocities were integrated from accelerometer placed at the excitation bearing, at point 8 in Figure 1, close to the proximity probes. This approach was adopted to avoid unsuitable velocity signals that can affect the control signals due to the amplified noise coming from the numerical time derivative of the displacement signals and due to the phase lags obtained by the use of low pass filters, commonly used to avoid the noise. A parameter identification (modal) test aided by the electromagnetic shaker was carried out to characterize the dynamic behavior of the flexible rotor-bearing system at each orthogonal direction for all considered operational condition of Table 2, except for the cases $\# 1$ (a), \#2(a) and \#3(a) with the lowest pressure. The experimental procedure was as follows:

- The test rig is run under conventional lubrication for each angular velocity until the steady-state (s$\mathrm{s}$ ) is reached. Then, the modal test is performed in both orthogonal directions. These benchmark records are identified as the passive cases.

- The test rig is run under hybrid lubrication for each angular velocity and pressures considered until the s-s condition is reached. Then, the modal test is performed in both orthogonal directions. These records are identified as the leakage case.

- Once the s-s is reached for each operational case and after the leakage cases, the different PD controllers are tested with the test rig running under feedback-controlled lubrication. Then, for all controllers the modal test is performed. These records are identified as the active cases with the controllers of Table 3.

Table 3: Synthesized PD controller gains from the stabilizing area $\boldsymbol{D}$ of Figure 5 within the servovalves restrictions.

\begin{tabular}{lll}
\hline \hline & $k_{p}[\mathrm{~V} / \mu \mathrm{m}]$ & $k_{d}[\mathrm{Vs} / \mu \mathrm{m}]$ \\
\hline \hline PD controller \#1 & 0.006 & $2 \cdot 10^{-5}$ \\
\hline PD controller \#2 & 0.010 & $2 \cdot 10^{-5}$ \\
\hline PD controller \#3 & 0.006 & $3 \cdot 10^{-5}$ \\
\hline \hline
\end{tabular}

\subsection{Experimental FRFs}

Figure 7 shows the experimental FRFs obtained in the horizontal direction for the cases \#1 of Table 2, i.e. 1000 RPM. In green color is depicted the dynamic response of the system under passive or conventional lubrication as a benchmark. In black and grey are depicted the response under hybrid lubrication for 50 and 70 bar respectively, identified as the leakage case while in red and dark red are depicted the system response under active or feedback-controlled lubrication with the PD controller \#1 of Table 3 for the same pressures. Results for the remaining PD controllers have been omitted since they do not present improvements compare to PD controller \#1. From the graph, it can be noticed that the system response is effectively reduced on the resonant zone when the PD controller \#1 is used. This reduction is more evident as the pressure of the supply unit is increased. To make more evident the pressure effect, it has been also included with blue and dark blue the responses under active lubrication with 90 bar and 100 bar respectively. A reduction of about $30 \%$ can be obtained when the peak amplitudes of the active case with 100 bar is compared against the passive one. Figure 8 shows the experimental FRFs obtained in the vertical direction for the case \#2 of Table 2, i.e. 2500 RPM. The same color description has been used in this figure. Unlike the horizontal direction, in the vertical one there is present a second resonant zone around $165 \mathrm{~Hz}$. The PD controller \#1 in the vertical direction seems to be acting mainly over the first resonant zone, same than for the horizontal case, for which it can be stated that a reduction of the system response is obtained below $120 \mathrm{~Hz}$. The results for case \#3 have not been reported because they are highly affected by noise, obtaining a poor coherence.

\section{CONCLUSIONS}

Based on the experimental results obtained in this paper, the following conclusions can be summarized regarding the feedback-controlled lubrication applied to flexible rotor-bearing systems:

- The feedback-controlled or active lubrication based on PD controllers can be used to reduce the lateral vibration of a flexible-rotor bearing system supported by an active TPJB improving its dynamic performance.

- The effectiveness of the vibration reductions around the equilibrium position, strongly depend on the machine operational conditions as well as on the orthogonal directions on which these reductions are sought. It has been noticed that the effectiveness of the PD controller on reducing the lateral vibration can be significantly improved as 

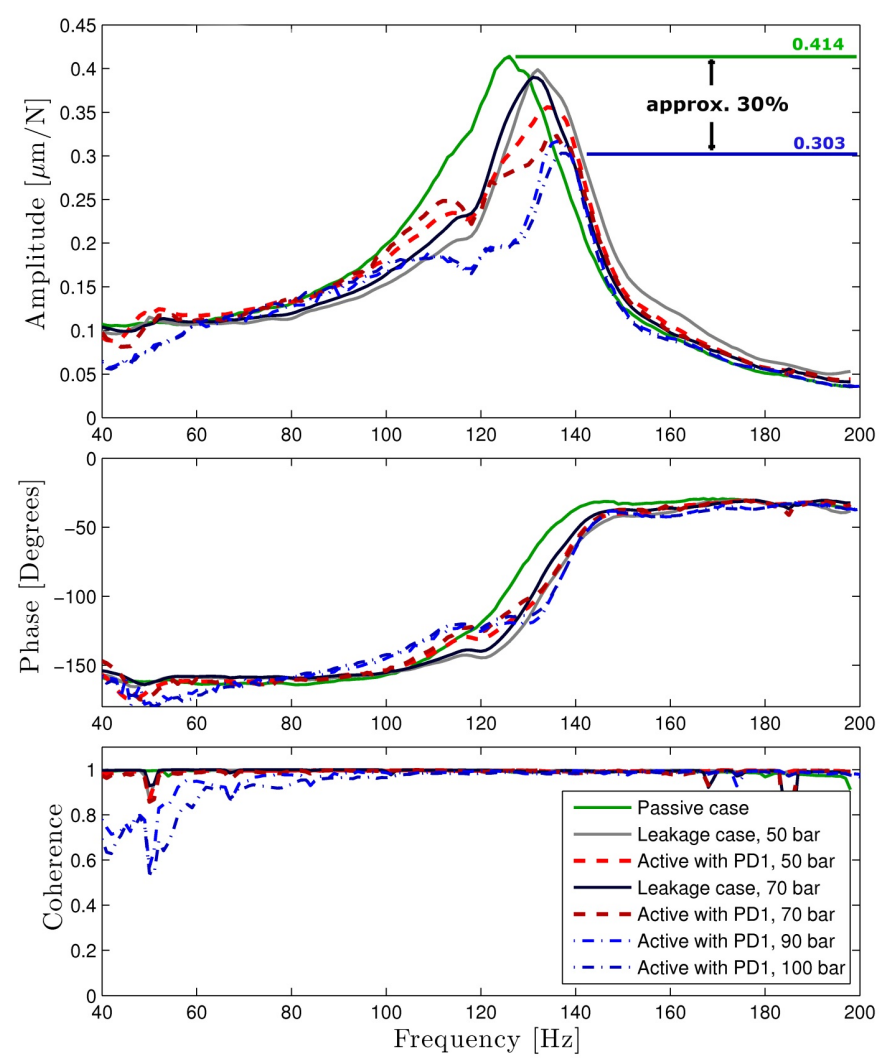

Figure 7: Experimental FRFs comparison in the horizontal direction for the case \#1 of Table 2, 1000 RPM. (-) Passive lubrication. (-) Hybrid lubrication, leakage case with 50 bar. (-) Active lubrication with PD controller 1, 50 bar. (-) Hybrid lubrication, leakage case with 70 bar. (-) Active lubrication with PD controller 1, 70 bar. (-.) Active lubrication with PD controller 1, 90 bar. (-.) Active lubrication with PD controller 1, 100 bar.

the pressure set on the high pressure supply unit is increased.

- A simple PD controller can be used for such a goal and their proportional and derivative gains can be synthesized optimizing an objective function within the stabilizing gain domain or from a narrowed restricted subdomain due to the experimental control signals restrictions. A model-free approach of the plant dynamics based on the measured FRFs via servovalves provides the required plant information for the controller design aim.

\section{REFERENCES}

1. Wasilczuk M., 2013, "Should we seek further improvement of fluid film bearings - what for and how ?," 12th EDF-Pprime Workshop, pp. 1-12.

2. Hagg A. C., 1946, "The influence of oil-film journal bearings on the stability of rotating machines," Journal of Applied Mechanics. Trans. ASME, 13(3), pp. A211-A220.

3. Ulbrich H., and Anton E., 1984, "Theory and application of magnetic bearings with integrated
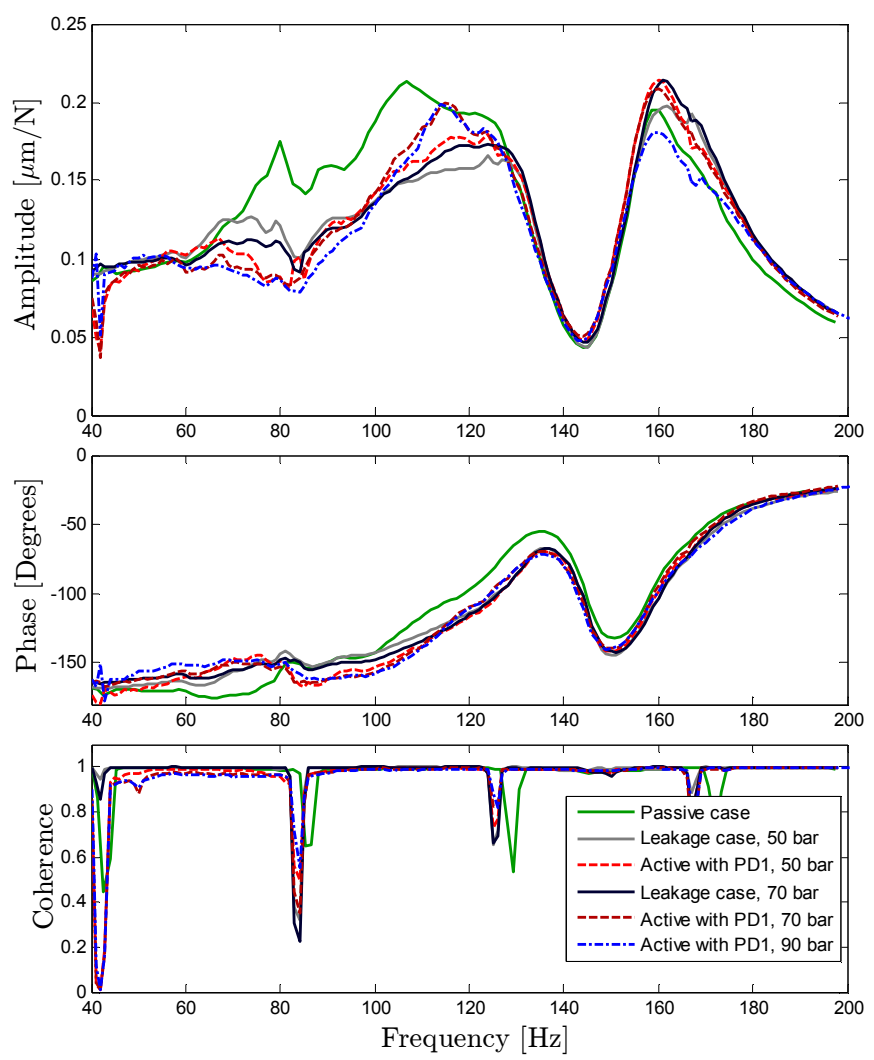

Figure 8: Experimental FRFs comparison in the vertical direction for the case \#2 of Table 2, 2500 RPM. (-) Passive lubrication. (-) Hybrid lubrication, leakage case with 50 bar. (--) Active lubrication with PD controller 1, 50 bar. (-) Hybrid lubrication, leakage case with 70 bar. (--) Active lubrication with PD controller 1, 70 bar. (-.) Active lubrication with PD controller 1, 90 bar.

displacement and velocity sensors," IMechE 1984 C299/84, pp. 543-551.

4. Ulbrich H., and Althaus J., 1989, "Actuator Design for Rotor Control," 12th Biennial conference on Mechanical Vibration and Noise. Montreal, Quebec, Canada, pp. 17-22.

5. Palazzolo A. B., Lin R. R., Alexander R. M., Kascak A. F., and Montague J., 1991, "Test and Theory for Piezoelectric Actuator-Active Vibration Control of Rotating Machinery," Journal of Vibration and Acoustics, 113(April), pp. 167-175.

6. Althaus J., and Ulbrich H., 1992, "A fast hydraulic actuator for active vibration control," IMechE 1992, C432/045, pp. 141-148.

7. Santos I. F., 1994, "Design and evaluation of two types of active tilting-pad journal bearings," The active control of vibration, C.R. Burrows, P.S. Keogh (eds.) Mechanical Engineering Publications Limited, London, England, pp. 79-87.

8. Santos I. F., and Russo F. H., 1998, "Tilting-Pad Journal Bearing With Electronic Radial Oil Injection," Journal of Tribology, Trans. ASME, 120(July), pp. 583-594.

9. Haugaard A. M., and Santos I. F., 2010, "Elastohydrodynamics Applied to Active Tilting- 
Pad Journal Bearings," Journal of Tribology, Trans. ASME, 132(2), pp. 021702-1-10.

10.Varela A. C., and Santos I. F., 2012, "Performance improvement of tilting-pad journal bearings by means of controllable lubrication," Mechanic \& Industry, 13(1), pp. 17-32.

11.Cerda Varela A., Bjerregaard Nielsen B., and Santos I. F., 2013, "Steady state characteristics of a tilting-pad journal bearing with controllable lubrication: Comparison between theoretical and experimental results," Tribology International, 58, pp. 85-97.

12.Santos I. F., and Scalabrin A., 2003, "Control System Design for Active Lubrication With Theoretical and Experimental Examples," Journal of Engineering for Gas Turbines and Power, 125(1), pp. 75-80.

13.Nicoletti R., and Santos I. F., 2003, "Linear and non-linear control techniques applied to actively lubricated journal bearings," Journal of Sound and Vibration, 260(5), pp. 927-947.

14.Nicoletti R., and Santos I. F., 2005, "Frequency Response Analysis of an Actively Lubricated Rotor/Tilting-Pad Bearing System," Journal of Engineering for Gas Turbines and Power, 127(3), pp. 638-645.

15.Salazar J.G., and Santos I. F., 2014, "Exploring Integral Controllers in Actively-Lubricated TiltingPad Journal Bearings". Submitted to Tribology International. TRIBINT-D-14-00130.

16.Santos I. F., and Nicoletti R., 2008, "Control System Design for Flexible Rotors Supported by Actively Lubricated Bearings," Journal of Vibration and Control, 14(3), pp. 347-374.

17.Gryazina E. N., 2004, "The D -Decomposition Theory," Automation and Remote Control, 65(12), pp. 1872-1884.

18.Gryazina E. N., and Polyak B. T., 2006, "Stability regions in the parameter space: D-decomposition revisited," Automatica, 42(1), pp. 13-26.

19. Gryazina E. N., Polyak B. T., and Tremba A. A., 2008, "D-decomposition technique state-of-theart," Automation and Remote Control, 69(12), pp. 1991-2026.

20.Buttini T. M., and Nicoletti R., 2011, "Rotor Lateral Vibration Control: A Stability and Performance Analysis Based on a Model Free Approach," 18th International Congress on Sound \& Vibration, pp. 1-8.

21.Buttini T. M., and Nicoletti R., 2012, "SelfIdentification Algorithm for the Autonomous Control of Lateral Vibration in Flexible Rotors," International Journal of Rotating Machinery, 2012, pp. 1-13.

22.Rho B.-H., and Kim K.-W., 2002, "The effect of active control on stability characteristics of hydrodynamic journal bearings with an axial groove," ImechE Journal of Mechanical Engineering Science, 216(9), pp. 939-946.

23. Bristol E. H., 1966, "On a New Measure of Interaction for Multivariable Process Control," IEEE Trans. Automat. Contr., 11, pp. 133-134.

24.Ziegler J. G., and Nichols N. B., 1942, "Optimum Settings for Automatic Controllers," Trans. ASME, 64(8), pp. 759-768.

25.Ho M.-T., Datta A., and Bhattacharyya S. P., 1997, "A Linear Programming Characterization of All Stabilizing PID Controllers," Proceeding of the American Control Conference, pp. 3922-3928.

26.Keel L. H., Member S., and Bhattacharyya S. P., 2008, "Controller Synthesis Free of Analytical Models: Three Term Controllers," IEEE Transactions on Automatic Control, 53(6), pp. 1353-1369.

27.Li Y., Sheng A., and Wang Y., 2008, "Synthesis of PID-type controllers without parametric models: A graphical approach," Energy Conversion \& Management, 49(8), pp. 2392-2402.

28.Santos I. F., 2011, "On the future of controllable fluid film bearings," Mécanique \& Industries, 281, pp. 275-281.

29.Cominos P., and Munro N., 2002, "PID controllers: recent tuning methods and design to specification," IEE Proc.-Control Theory Appl., 149(1), pp. 46-53.

30.Skogestad S., and Postlethwaite I., 2001, Multivariable Feedback Control: Analysis and Design, John Wiley \& Sons. 